\title{
Perceived stigma among caregivers of mentally ill patient: A descriptive cross-sectional study
}

Khanal P ID

Pratibha Khanal, Lecturer, Department of Nursing, Kathmandu Medical College, Sinamangal, Kathmandu, Nepal.

\begin{abstract}
Background: Stigmatising experience related to mental illness is not only confined to the patient but also experienced by their caregivers such as family members and friends. Caregivers feel down and helpless about their affiliation with stigma related to mental illness. Various research studies show that stigma related to mental illness have negative influence on caregivers which leads to concealing the status of mentally ill relatives.

Objective: This study aimed to assess the level of perceived stigma among the caregivers of mentally ill patients.

Methods: A descriptive cross-sectional study was conducted at outpatient and inpatient departments of Psychiatry, Kathmandu Medical College from 30th January to August 30th 2020. Two hundred and sixteen respondents were chosen conveniently. Face to face interview was conducted using standard tool ‘Devaluation Consumers Families Scale' to assess the perceived stigma among caregivers of mentally ill patients.

Results: Perceived stigma among the caregivers of mentally ill patients was found to be medium (mean score 15.8 \pm 2.8 ). The caregivers perceived the community looking down on the families with mentally ill relatives (community rejection). The mean score was low $(2.1 \pm 0.8)$ on "uncaring parents" which indicates that the respondents did not agree that parents of mentally ill patients were less responsible and caring than others.

Conclusion: Caregivers of mentally ill patient perceive stigma in various forms which affects the usages of health facilities, care and support towards mentally ill relatives.
\end{abstract}

Key words: Caregivers; Mentally ill; Perceived; Stigma.

\section{INTRODUCTION}

aregivers have a major role in care of mentally ill person. The overall activities of daily living, functionality and providing medication to mentally ill relatives depends upon their caregivers. ${ }^{1}$ General public

Access this article online
Website: www.jkmc.com.np
DOI: https://doi.org/10.3126/jkmc.v10i1.38971
HOW TO CITE
Khanal P. Perceived stigma among caregivers of mentally ill
patient: A descriptive cross-sectional study. J Kathmandu Med
Coll. 2021;10(1):43-6.

Address for correspondence

Pratibha Khanal

Lecturer, Department of Nursing

Kathmandu Medical College

Sinamangal, Kathmandu, Nepal.

E-mail: pratupeace1@gmail.com

Copyright $\odot 2021$ Journal of Kathmandu Medical College (JKMC)

ISSN: 2019-1785 (Print), 2091-1793 (Online)

(i) (8) This work is licensed under a Creative Commons Attribution-Non Commercial 4.0 International License. holds negative stereotypes and prejudice against mental illness and their caregivers. ${ }^{2}$ Society blames family members for development of mental illness. ${ }^{3}$ Stigma experienced by caregivers of mental illness varies from $43 \%$ to $83 \%$. ${ }^{4,5}$ Stigmatising experience is not only limited to family members but also by relatives and friends. ${ }^{6}$ Stigmatisation-beliefs is one of the causes of negative attitude towards mental illness. , $^{6,7}$

About tenth of adult population suffers from mental disorders at any one time. These disorders now account for about $12 \%$ of global impact of disability, and this will rise to $15 \%$ in upcoming years. Caregivers of mental illness such as schizophrenia, experience reduced social participation. $^{8}$

Study showed that $73 \%$ of caregivers had difficulty in continuing job and $51 \%$ of them thought that neighbours and colleagues neglected them due to their relative's illness. ${ }^{9}$

Stigma is an important factor that determines health and treatment seeking behaviour. ${ }^{10}$ Thus, understanding it helps to reduce negative impact on treatment process. 
Hence, this study aimed to assess the perceived stigma among caregivers of mentally ill patient.

\section{METHODOLOGY}

A descriptive, cross-sectional study was conducted at in-patient and out-patient departments of Psychiatry, Kathmandu Medical College from 30th January to 30th August 2020. Ethical clearance was obtained prior to data collection from the Institutional Review Committee (IRC) of Kathmandu Medical College (Ref. 200120206). Convenience sampling technique was used while selecting the caregivers of mentally ill patient. Two hundred and seventeen caregivers were included in the study after taking the prevalence of perceived stigma as $83 \%$, statistical formula of $n=Z^{2} p q / d^{2}$, where $d$ (allowable error $)=0.05, z$ (confidence level) $=1.96, p$ (prevalence of perceived stigma) $)^{11}=0.83$ and $q(1-p)=0.17$ but one of the respondent withdrew from the study thus 216 caregivers were taken. Data was collected using face to face interview technique from either of parents, siblings, family members and friends aged above 18 years whose duration of stay with the patient should be at least six months. Caregivers of patients with a diagnosis of substance use disorder, neurotic stress related and somatoform disorders were excluded from the study.

Socio-demographic and disease related data was collected using a structured questionnaire developed by researcher. While perceived stigma was assessed using standard tool Devaluation consumers families scale (DCFS). The DCFS evaluates perceived stigma towards families of those with mental illness. The DCFS comprises of total seven items and is divided into three domains community refusal, causal attribution, neglectingparents or uncaring parents. The DCFS is a four-point Likert scale where 1 is strongly disagree and 4 is strongly agree. The maximum score is 28 and minimum score is 7. Higher score indicates higher level of stigma among caregivers.

A written informed consent was obtained from all the respondents explaining the objectives, confidentiality, and full authority to withdraw their participation from study without any fear or clarification at any time during the study. Precautions were taken throughout the study to safeguard the rights and welfare of all the respondents.

Data was collected in Psychiatric outpatient department and ward. Collected data were checked for its completeness and accuracy. Data were coded and entered in SPSS Statistics for Windows, version 16.0 (SPSS Inc., Chicago, III., USA). Descriptive statistics like frequency, percentage, mean, and standard deviation were used to analyse the data.

\section{RESULTS}

The mean age of caregivers was found to be $38.7 \pm 13.06$ years. Majority 138 (62\%) of the caregivers were female and 199 (92.1\%) followed Hinduism as their religion. More than two thirds 77 (35.6\%) of the caregivers were from Brahmin ethnicity. Only 57 (26.4\%) of the caregivers had educational status more than higher secondary. More than half $136(62.9 \%)$ of the caregivers lived in nuclear family and 169 (78.2\%) were married. Nearly 67 (31\%) of caregivers were parents. Of all, 81 (37.5\%) of the caregivers relative were diagnosed with depressive disorder. Mean duration of illness was found to be 3.9 \pm 0.9 years where as mean years of caregiving by the relatives was $9.5 \pm 3.9$.

\section{Table 1: Socio-demographic and disease related} variables

$(n=216)$

\begin{tabular}{lcc}
\hline Variables & $\begin{array}{c}\text { Frequency } \\
\text { (Percentage) }\end{array}$ & Mean \pm SD \\
\hline Caregivers age in years & & $38.7 \pm 13.06$ \\
\hline Sex & & \\
Male & $82(38)$ \\
Female & $134(62)$ \\
Religion & \\
Hindu & $199(92.1)$ \\
Buddhist & $9(4.2)$ \\
Christian & $6(2.8)$ \\
Muslim & $2(0.9)$ \\
Ethnicity & \\
Brahmin & $77(35.6)$ \\
Chhetri & $57(26.4)$ \\
Newar & $26(12)$ \\
Others & $56(26)$ \\
Educational status & \\
Illiterate & $34(15.7)$ \\
Primary & $28(13)$ \\
Secondary & $52(24.1)$ \\
Higher Secondary & $45(20.8)$ \\
Above higher secondary & $57(26.4)$ \\
Family type & \\
Nuclear & $136(62.9)$ \\
Joint & $80(37)$ \\
Marital status & \\
Married & \\
Divorced & \\
Single & \\
Relationship with the & \\
patient & \\
Parent & \\
Spouse & \\
Sibling & \\
Children & \\
Others & \\
& \\
& \\
\hline
\end{tabular}




\begin{tabular}{|c|c|c|}
\hline \multicolumn{3}{|l|}{ Type of diagnosis } \\
\hline Schizophrenia & $30(13.9)$ & \\
\hline BPAD & $31(14.4)$ & \\
\hline Psychotic disorder & $74(34.3)$ & \\
\hline Depressive disorder & $81(37.5)$ & \\
\hline Age of onset of illness & & $28.5 \pm 15$ \\
\hline Duration of illness in years & & $3.9 \pm 0.9$ \\
\hline Years of caregiving & & $9.5 \pm 3.9$ \\
\hline $\begin{array}{l}\text { Duration of stay with } \\
\text { patient }\end{array}$ & & $20.9 \pm 10.24$ \\
\hline
\end{tabular}

Table 2: Perceived stigma among caregivers of mentally ill patient $(n=216)$

\begin{tabular}{lc}
\hline Perceived Stigma & Mean \pm SD \\
\hline Over all perceived stigma & $15.8 \pm 2.8$ \\
Domains of perceived stigma & \\
Community rejection & $8.6 \pm 2.4$ \\
Casual attribution & $5 \pm 1.3$ \\
Uncaring parents & $2.1 \pm 0.8$ \\
\hline
\end{tabular}

The overall perceived stigma among the caregivers was found to be medium $15.8 \pm 2.8$. Similarly the perceived stigma in three domains that is community rejection, casual attribution and uncaring patient was also calculated. The respondent perceived community rejection while caring for their mentally ill relative followed by casual attribution whereas respondents did not agree that parents of mentally ill patients are uncaring and less responsible than other parents.

\section{DISCUSSION}

This study showed that over all perceived stigma was medium with the mean score of $15.8 \pm 2.8$. This means that the caregivers felt stigmatised while caring a relative with mental illness. The findings of this study were in line with the study conducted in Nepal (2019), ${ }^{11}$ (2014), ${ }^{12}$ and Vellore, India (2019) ${ }^{10}$ which showed that caregivers felt burden and stigma having a relative with mental illness.

\section{REFERENCES}

1. Boge $K$, Zieger A, Mungee A, Tandon A, Fuchs L, Schomerus $G$, et al. Perceived stigmatization and discrimination of people with mental illness: A survey-based study of the general population in five metropolitan cities in India. Indian J Psychiatry. 2018 Jan-Mar;60(1):24-31. [PubMed | Full Text | DOI]

2. Angermeyer MC, Dietrich S. Public beliefs about and attitudes towards people with mental illness: A review of population studies. Acta Psychiatr Scand. 2006 Mar;113(3):163-79. [PubMed | Full Text | DOI]
The present study showed that most of the respondent perceived higher stigma in components like community rejection $8.6 \pm 2.4$ and casual attribution $5 \pm 1.3$. They felt that the community blames and rejects the caregivers of mentally ill patients. The findings of this study is congruent with the study conducted in Malaysia (2016) ${ }^{13}$ which showed that the caregivers perceived stigma in both the components of community rejection and casual attribution.

In this current study caregivers did not agree that most of the people believe that parents of children with mental illness are not as responsible and caring as other parents which falls under the component of 'uncaring parents'. This study findings are supported by the study conducted in Vellore, India (2019) ${ }^{10}$ and Malaysia (2016) ${ }^{13}$ both reported that most of the respondents did not believe in uncaring parents.

\section{CONCLUSION}

The study concludes that caregivers of mentally ill patients are subjected to various forms of stigma. Caregivers felt rejected by community if they have family members with psychiatric disorders. Similarly, the caregivers felt stigmatised in the domain of casual attribution that is blaming families for mental illness. Hence, there is a need for conducting stigma reduction program as stigma associated with mental illness can potentially interfere the treatment of mentally ill patients.

\section{ACKNOWLEDGEMENT}

The researcher would like to thank all the respondents included in this study for providing their valuable time and making this study possible. Researcher also thank Kathmandu Medical College for their help, support and platform for data collection.

Conflict of interest: None

Source(s) of support: None

3. Corrigan PW, Miller FE. Shame, blame, and contamination: A review of the impact of mental illness stigma on family members. J Fam Psychol. 2004;13(6):537-48. [Full Text | DOI]

4. Aakansha S, Mattoo S, Grover S. Stigma associated with mental illness: Conceptual issues and focus on stigma perceived by the patients with schizophrenia and their caregivers. Indian J Soc Psychiatry. 2016;32(2):134-42. [ Full Text | DOI]

5. Pandey S. Perception of stigma among caregivers of mentally ill people. Nepal Med Coll J. 2019 Nov 25;21(3):184-9. [Full Text | DOI] 
6. Lauber C, Rössler W. Stigma towards people with mental illness in developing countries in Asia. Int Rev Psychiatry. 2007 Apr;19(2):157-78. [PubMed | Full Text|DOI]

7. Del Goleto S, Younès N, Grevin I, Kostova M, Blanchet A. Qualitative analysis of the experience of patients with schizophrenia' family caregivers at different stages of disease progression. Ann Med Psychol. 2019 Oct;177(8):740-8. [Full Text | DOI]

8. Daumerie N, Vasseur Bacle S, Giordana JY, Mannone CB, Caria A, Roelandt JL. Discrimination perceived by people with a diagnosis of schizophrenic disorders. International study of discrimination and stigma outcomes. Encephale. 2012 Jun;38(3):224-31. [PubMed | Full Text | DOI]

9. Hadera E, Salelew E, Girma E, Dehning S, Adorjan $\mathrm{K}$, Tesfaye M. Magnitude and associated factors of perceived stigma among adults with mental illness in Ethiopia. Psychiatry J. 2019 Mar;27. [Full Text | DOI]
10. Guttikonda A, Shajan A, Hephzibah A, Jones A, Susanna J, Neethu $S$, et al. Perceived stigma regarding mental illnesses among rural adults in Vellore, Tamil Nadu, South India. Indian J Psychol Med. 2019 MarApr;41(2):173-7. [PubMed | Full Text | DOI]

11. Lamichhane RK. Stigma perceived by family members of psychiatric patients attending outpatient department of a teaching hospital. J Patan Acad Heal Sci. 2019;6(2):64-9. [Full Text | DOI]

12. Neupane D, Dhakal S, Thapa S, Bhandari PM, Mishra SR. Caregivers' attitude towards people with mental illness and perceived stigma: A cross-sectional study in a tertiary hospital in Nepal. PLoS. 2016 Jun 23;11(6) :e0158113. [PubMed | Full Text | DOI]

13. Ong HC, Ibrahim N, Wahab S. Psychological distress, perceived stigma, and coping among caregivers of patients with schizophrenia. Psychol Res Behav Manag. 2016 Aug16;9:211-8. [PubMed | Full Text | DOI] 